\title{
AN ACCELERATED SUBCONTRACTING AND PURCHASING (ASAP) MODEL FOR CONSTRUCTION PROJECTS USING XML/XSL STANDARDS
}

\author{
Pao-Hung LIN ${ }^{a}$ and Hui-Ping TSERNG ${ }^{b}$
}

\author{
a Ph.D. Candidate, Dept. of Civ. Engrg., National Taiwan Univ, R.O.C.
} b Assoct. Prof., Dept. of Civ. Engrg., National Taiwan Univ, R.O.C.

\begin{abstract}
Based on the characteristics of highly specialized corporation in construction industry, it's a very crucial and important practice to select appropriate subcontractors to implement specific subprojects. In this research, the overall subcontracting supply chain of a construction project is considered as a global procurement system and an optimal combination of subcontractors can be obtained within this system. Combined the quick response mechanism of information technology with investment portfolio theory in financial management, an integrated XML/XSL of Accelerated Subcontracting And Purchasing (ASAP) model was proposed. The ultimate goal of this study is to develop a web-based decision support system for general contractors to accurately decide an appropriate trade-off between risk and revenue for different subcontracting combinations through omnipresent internet.
\end{abstract}

Keywords: E-Commerce (EC), Subcontracting, XML, XSL, Quick Response, Supply Chain Management (SCM) 


\section{INTRODUCTION}

In today's globalized surroundings of ever increasing competitiveness and decreasing resources, each business is tend to utilize its own relatively competitive advantage to promote business values and get beneficial effects in specific industry. From the early time of 90', the activities of business downsizing and reengineering are very fashionable and even like rising winds and surging because businesses are aware of that just keeping the core competence and kick out redundancy is the exact way to win. So, using the way of outsourcing to obtain limited resources, to reduce operation cost, and to disperse risk has been the dominantly competitive strategy.

There were also many researches $[1,2,3,4,5]$ focusing on the subcontracting behavior in construction industry, including from the view point of transaction cost [1], partnering [2], vertical integration and so on. So many research results demonstrate that: for reasons of capacity, specialization, buffer, scattering capital, or reducing risk, subcontracting project has been the main developing stream to acquire necessary resources and implement specific subproject for construction industry. For the time being, the general contractors have been playing the role of integrator and manager more than a real constructor. There is no doubt that selecting a suitable subcontractors team becomes the most tricky strategy at any stage of project life cycle. However, since the internet came to rise in 90 ', the traditional transaction model has been undergoing a thoroughly revolutionary change. Supported by the information technology, people can not only deal with the complicated transaction which can not be done, but can completely reduce the information asymmetry and unfair situation in traditional market. By the nature of completely revealed information, the transaction atmosphere of virtual ecommerce market is quite different with that in physical market, greatly preventing the transaction uncertainty and obstacles of speculator. It is a worthy of concerning subject that the impact and correlation between general contractor and subcontractors in the post information era.

\section{PROBLEM STATEMENTS}

The traditional way to select subcontractors are always under the limited consideration of quasi-firm structure [3]. That is, most contractors have their own long-term cooperative firms or partners to implement a construction project. There are some advantages existing in quasi-firm structure, including flexible, stable, credible relationship and saving transaction cost. However, the general contractors are deeply dependant on specific subcontractors more and more, and are not good for controlling and managing projects in the long run. On the other hand, ignoring the interactions and integrated effects among subcontractors, the traditional subcontracting strategy always focuses on individual subproject one by one. The most problem existing in this strategy is that limited sample space of selection will probably lead to an inefficient combination of subcontractors.

This research looks the overall subcontracting supply chain as a whole system to consider the globally optimal combination of subcontractors. Combined the quick response mechanism of information technology with investment portfolio theory in financial management, an accelerated subcontracting and purchasing (ASAP) model was proposed. The proposed ASAP model is intended to provide a new means for construction organizations to minimize risk and uncertainty in the management of subcontracting control and thereby improve their cost and schedule performance based on specific or historical data. The ultimate purpose of this study is to develop a web-based decision support system which can perform the scenario simulation for general contractors to easily decide an even point between risk and revenue for different subcontracting combinations.

\section{CONSTRUCTION INFORMATION TECHNOLOGY AND STANDARDS}

Construction industry is a less computerized industry than the others. Many deficiencies can be greatly improved by using advanced information technologies. Adding the IT to promote decision quality, ASAP would like to break the old thinking frame in subcontracting construction projects. ASAP is provided with the functions of real time decisionmaking and acceptance of quotation through internet. In facing of a vast amount of potential construction bidders, ASAP first need to establish the communication standards to exchange information with each other, either within the stage of pushing bid or accepting bid quotation. Different subcontractors have their own different management information system (e.g. hardware and software). Information can not be encrypted and shared without overcoming the problems of different information system and compatibility of document format. It is a crucial task to implement a development environment which is independent from different subcontractors. So, the development of ASAP is under the guidance of that each business can integrate its own enterprise resource planning (ERP) system without needing any special facilities and can have an accurate access to the latest information through the information sharing network. The following will introduce some standards of documentation:

3.1 SGML (Standard Generalized Markup Language) 
SGML is an international standard for the definition of device-independent, system-independent methods of representing texts in electronic form.[7] SGML was adopted as a standard by the International Organization for Standardization (ISO) in 1986, and referenced by ISO 8879 regulation. SGML is a metalanguage, that is, a means of formally describing a markup language. It is used to describe the structure of a document. More exactly, structure, content and display are all separated in SGML. It had been used for many years in sophisticated and highly complex publishing applications. The most disturbing problem for SGML is that it is cumbersome and inefficient to transport in network. Besides, SGML is very complicated to understand in a short time and is not easily to be maintained by the common business.

\subsection{XML (eXtensible Markup Language)}

XML has been developed by the World Wide Web Consortium (W3C) in 1996. In fact, XML is a direct descendant of SGML. However, XML's design was conducted by looking at the advantages and weaknesses of SGML but without all the complex and rarely used features. That is, the designers of XML try to cut out everything in SGML that was not needed for Web delivery. The result is a much simpler and slimmed down language. XML defines a universal standard for electronically exchanging data for the internet and web applications and is supported by major IT vendors. Also, XML is a text-based format that lets developers don't need any particular operating system or hardware. Information can be more accessible and reusable through internet. Furthermore, unlike in HTML, structure and display are all defined by inflexible tags, XML has a flexible strength to allow users (groups of people or organizations) to define their own customized markup languages for exchanging information in specific domain. In addition, XSL (eXtensible Style Language) defines the specification for an XML document's presentation and appearance. It is used to transform XML-based data into HTML or other presentation formats. XSL is the proposed style language for XML documents . Basically, XSL is a subset of DSSSL (Document Style Semantics and Specification Language) which is a style language used primarily with SGML [7]. With the aids of XSL, we can distribute different content presentation to different viewers and make XML more flexible.

\subsection{EDI (Electronic Data Interchange)}

EDI can be regarded as the grandfather of the electronic commerce. The appearance of EDI is for setting up a standard for data exchange, especially for different organizations and fields. EDI has still not been popular and widely applied since 60' up to date. There are many reasons or constraint existing as following: the initial setup cost is expensive, the transportation media are limited, the establishment of standard is time-consuming, and only parts of automation are reached. Nevertheless, by using standards for components of an XML document and adding style information to XML document, XML/EDI documents and their included objects can be exchanged, viewed, searched, catalogued, and routed. The XML/EDI framework provides all the fundamental building blocks of e-commerce. [8]

Table1. Comparison of Standards of Information Exchange [11]

\begin{tabular}{|c|c|c|c|c|c|c|}
\hline Standard Item & & Taiwan & U.S.A & Europe & Australia & Malaysia \\
\hline Electronic Data Interchange & EDI & YY & $\mathrm{N}$ & UU & $\overline{\mathrm{Y}}$ & YY \\
\hline $\begin{array}{l}\text { Office Document Architecture/ Office } \\
\text { Document Interface Format }\end{array}$ & $\begin{array}{l}\text { ODA/ } \\
\text { ODIF }\end{array}$ & $\bar{Y}$ & $\mathrm{~N}$ & $\bar{U}$ & $\mathrm{Y}$ & $\mathrm{N}$ \\
\hline Standard Generalized Markup Language & SGML & $\mathrm{Y}$ & $\mathrm{Y}$ & $\mathrm{U}$ & $\mathrm{Y}$ & $\mathrm{N}$ \\
\hline Computer Graphics Metafile & CGM & $\mathrm{Y}$ & $\mathrm{Y}$ & $\mathrm{U}$ & $\mathrm{Y}$ & $\mathrm{N}$ \\
\hline Portable Document Delivery Format & PDDF & $\mathrm{N}$ & $\mathrm{Y}$ & $\mathrm{U}$ & $\mathrm{Y}$ & $\mathrm{N}$ \\
\hline Initial Graphic Exchange Specification & IGES & $\mathrm{N}$ & $\mathrm{Y}$ & $\mathrm{U}$ & $\mathrm{Y}$ & $\mathrm{N}$ \\
\hline $\begin{array}{c}\text { Standard for the Exchange of Product } \\
\text { Model Data }\end{array}$ & STEP & $\mathrm{N}$ & $\mathrm{Y}$ & $\mathrm{U}$ & $\mathrm{Y}$ & $\mathrm{N}$ \\
\hline Standard Page Description Language & SPDL & $\mathrm{N}$ & $\mathrm{N}$ & $\mathrm{U}$ & $\mathrm{Y}$ & $\mathrm{N}$ \\
\hline $\begin{array}{l}\text { Electronic Manuscript Preparation \& } \\
\text { Markup }\end{array}$ & EMPM & $\mathrm{N}$ & $\bar{Y}$ & $\overline{\mathrm{U}}$ & $\mathrm{N}$ & $\mathrm{N}$ \\
\hline Spatial Data Transfer Standard & SDTS & $\mathrm{N}$ & $\mathrm{N}$ & $\mathrm{U}$ & $\mathrm{Y}$ & $\mathrm{N}$ \\
\hline $\begin{array}{l}\text { Digital Geographic Information Exchange } \\
\text { Standard }\end{array}$ & DIGEST & $\mathrm{N}$ & $\mathrm{N}$ & $\bar{U}$ & $\mathrm{Y}$ & $\mathrm{N}$ \\
\hline $\begin{array}{l}\text { Specification for Data Descriptive File for } \\
\text { Information Interchange }\end{array}$ & SDDFII & $\bar{Y}$ & $\mathrm{~N}$ & $\bar{U}$ & $\bar{U}$ & $\mathrm{~N}$ \\
\hline Joint Photographic Experts Group & JPEG & $\mathrm{Y}$ & $\mathrm{Y}$ & $\mathrm{U}$ & $\mathrm{U}$ & $\mathrm{N}$ \\
\hline Moving Picture Image Group & MPEG & $\mathrm{Y}$ & $\mathrm{Y}$ & $\mathrm{U}$ & $\mathrm{U}$ & $\mathrm{N}$ \\
\hline Joint Bi-level Image Group & JBIG & $\mathrm{Y}$ & $\bar{U}$ & $\mathrm{U}$ & $\mathrm{U}$ & $\mathrm{N}$ \\
\hline Font Information Interchange & FII & $\mathrm{Y}$ & $\mathrm{N}$ & $\mathrm{U}$ & $\mathrm{U}$ & $\mathrm{N}$ \\
\hline
\end{tabular}

(Note: Y denotes "standard has been established"; N denotes "not"; U denotes "unknown") 
Comparisons of the establishing status of information exchange standards among some countries are listed in table 1. Because XML brings so much power and flexibility to web-based applications for exchanging structured data, we will use XML as the document standard in developing ASAP model.

\section{FRAMEWORK OF ASAP MODEL}

ASAP adopts the three-tier architecture of database management system which is widely applied in recent years as the developing system framework. The three-tier architecture combines the merits of centralized processing and client-server structure. It utilizes the property of separating user's interface with business logic model, and reduces the dependence between application program and database. It is a very flexible and effective structure for database updating, renewing, and remodeling.

The three tiers include the presentation, business logic, and data tiers. The presentation tier in ASAP is mainly composed by DBA's (Database Administrator) and common users' two interfaces. It is the media by which user can communicate with web server and database. The business logic tier operates the main application functions, such as computing, querying, and graphing. The data tier can directly retrieve/save any information from/to database. ASAP system uses the Open Database Connection (ODBC) as the end interface with database, and can use ACCESS, SQL Server and related supporting database. The framework and processing flow of ASAP are demonstrated by figure1. All the client end user can reach any ASAP's function just through web browser at any time in any place all over the wortd. Standing on the view point of decisiongmaker of subcontracting management, ASAP not nery provides a completely portable decision supporb systen to general contractor but greatly enhance the decision quality to a real-time scale. On the other hand, a very fair and effective virtual transaction market environment is also established for interested bidders. The ASAP's processing flow includes the following steps:

Step1:General contractor pushes related tender information to the website throwoh the internet in XML document format.

Step2:The interested bidders downtc Step3:The interested bidders sub ASAP system.

Step4:General contractor retrieveso proceed the simulatio subcontractor combination. $\overline{\stackrel{\leftrightarrow}{q}}$

Step5:The computation is ongoing, transferred between business logic tier and database.

Step6:ASAP screens to the optimal combination of subcontractors according to the criteria set decision-maker.

Step7:General contractor sends con bidders, and communication are all in XML document.

\section{THEORY FUNDATION OF ASAP DECISION MODEL}

ASAP regards the subcontracting activities as the decision behaviors of specific investment portfolio. Every combination of subcontractors is like an asset collection in capital market. ASAP will automatically estimate the relative risk versus it's revenue according to specific "risk basis" which is assigned by decision-maker at the beginning of subcontracting simulation. There are three kinds of "risk basis" setup in ASAP:

(1) Basis on CAPP's historical performance database: The research of Continuous Assessment of Project Performance (CAPP) was performed by American Construction Industry Institute (CII) in 1996 $[9,10]$. CAPP uses continuous or time-dependent variables to predict project cost and schedule outcomes from the start of detailed design through construction completion. A continuous variable is defined as a time-dependent quantity whose value can be collected at several points during the course of a project. From the survey of 54 projects of 76 variables, CAPP demonstrates a significant difference between the "successful" S-curves and "less-than-successful" ones. CAPP has described a process by which continuous variables can be collected, analyzed, and predictions of project success made. Because CAPP has a detailed database information, ASAP adopts it as one of the risk basis evalate the whole project perfornance. \& $ه$

(2) B sis on enomicaliy optimal efficiency:

\&his $\otimes$ basis assumes the general contractor's Expenditure amount on specific project has nothing to do $\$$ th ${ }^{\otimes}$ roject's $\$$ proceeding schedule. That ${ }^{\circledR}$ is, the plannedocost expenditure is uniform distribution, ar there is no any additional variable cost neeg to be paid $\otimes$

(3:) Basis on internal historical experience:

This basis is subjectively assigned by decisionmaker according to professional judgement of general contractor's expeisknce on certain project type.

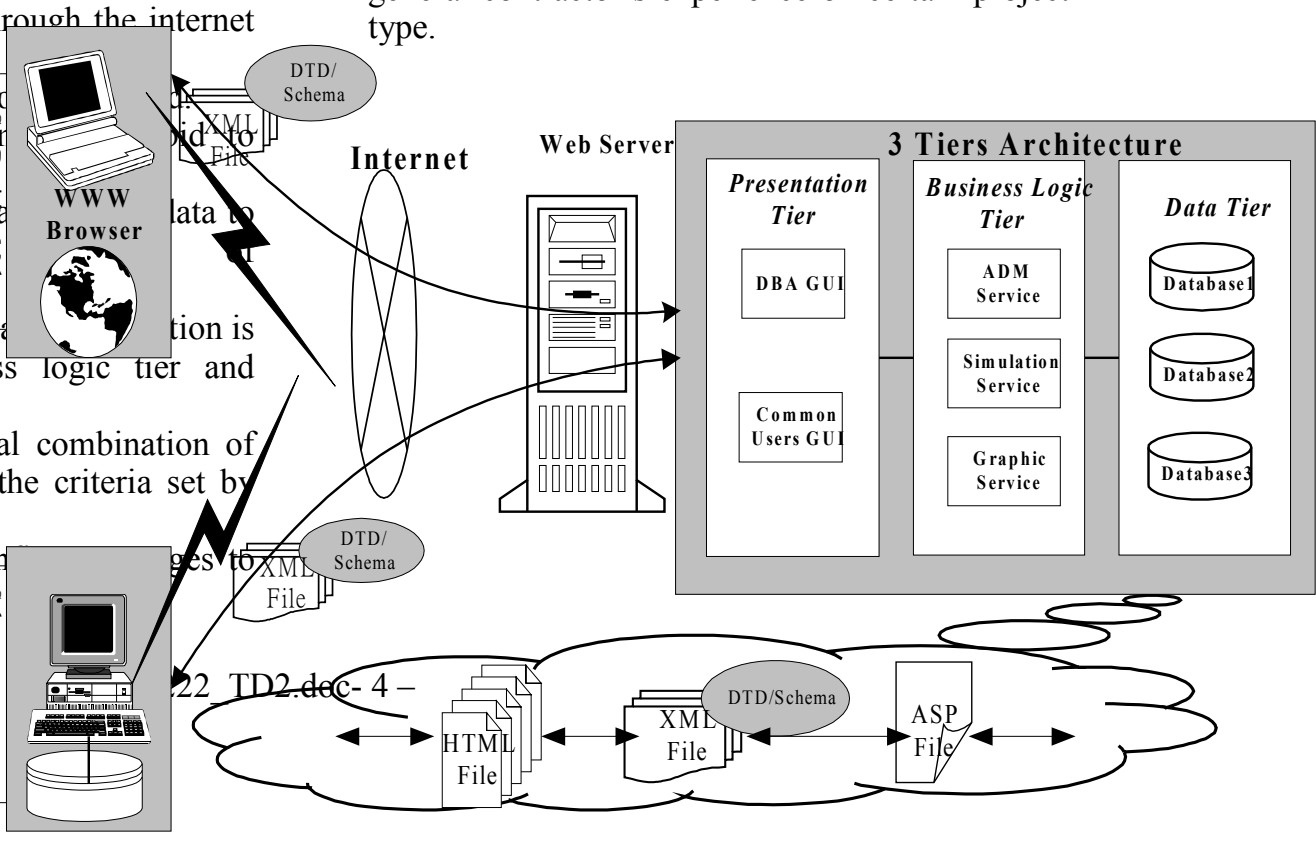




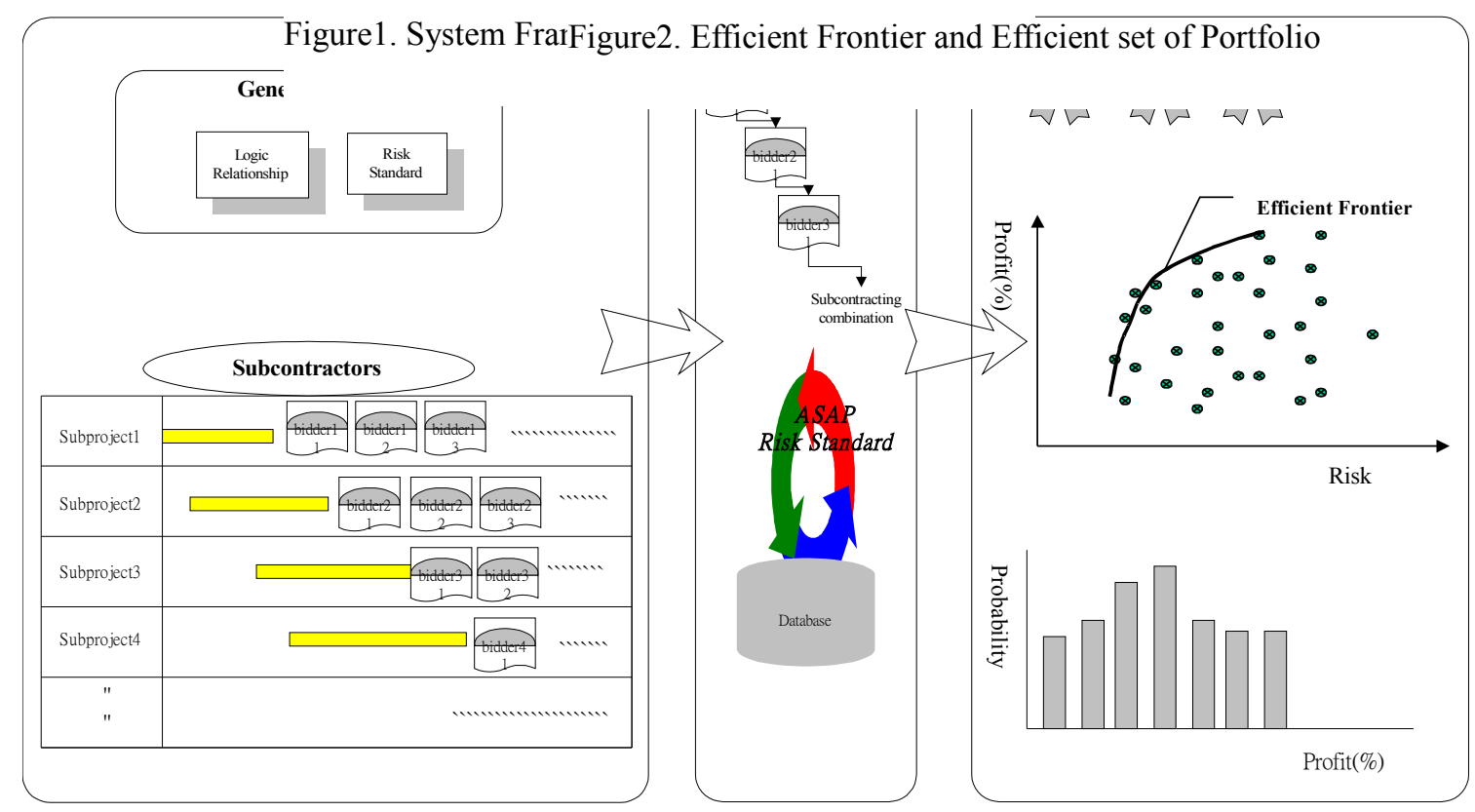

The ASAP input requirements for bidders include basic bidder's resume, bid price, scheduling plan and the most importantly financial loading distribution curve which is the dominant key factor to influence the bidding result for specific subproject. Besides, the risk basis is the required input for general contractor. ASAP will integrate all the possible situations of subcontracting combination for the whole project to analyze risk degree and reflect it on the plane of risk versus revenue. Based on the theory of investment portfolio, the efficient frontier can be graphed and established as figure2. The physical meaning of efficient frontier is that the subcontracting combination only located on the frontier is an efficient set of portfolio. It implies that any selection on the frontier curve general contractor can win the highest expected revenue under any specific risk degree or will suffer from the lowest risk under specific expected revenue. The ASAP system's input and output can be simply expressed as figure3.

\section{Efficient Frontier}

Specific Combination of Subcontractors 


\section{SYSTEM}

The development of ASAP system is constructed on the software platform of MS Windows NT Server 4.0 and PC/Workstation. Except for the application of CAPP database, the database end can adopt MS ACCESS or SQL Sever as the accommodation of bidding information. The developing softwares of interface will include Visual Basic, Javascript, Active Server Pages, and integrate with XML and Web Browser. The XML-Schema draft used to communicate the bid information is originated as following:

\section{Subcontract XML schema}

$<$ ? $\mathrm{xml}$ version $=" 1.0 "$ ? $>$

$<$ !--Generated by CEM Research Group2000 edi.1,

National Taiwan University.

Conforms to XML Data subset for IE 5-->

$<$ Schema name="SUBCONTRACT" xmlns="urn:schemasmicrosoft-com:xml-data"

xmlns:dt="urn:schemas-microsoft-com:datatypes">

$<$ ElementType name $=$ "SUBCONTRACT"

content $=$ "eltOnly" order $=$ "seq">

$<$ element type="BIDDER" minOccurs="1" maxOccurs $=" 1 " />$

$<$ element type="PROJECT" minOccurs="1"

maxOccurs $=" * " />$

$</$ ElementType $>$

$<$ ElementType name="BIDDER" content="eltOnly" order $=$ "seq" $>$

$<$ element type="SUBCONTRACTOR" minOccurs="1"

$\operatorname{maxOccurs}=" 1 " />$

$<$ element type="REPRESENTATIVE" minOccurs="1"

maxOccurs $=" 1 " />$

$<$ element type="ADDRESS" minOccurs="1"

maxOccurs $=" 1 " />$

$<$ element type $=$ "PHONE" minOccurs="1"

maxOccurs $=" 3 " />$

$<$ element type="E-MAIL" minOccurs="1"

$\operatorname{maxOccurs}=" 1 " />$

$<$ element type="FAX" minOccurs="1" maxOccurs="1"/>

$<$ ElementType $>$

$<$ ElementType name="SUBCONTRACTOR"

content $=$ "textOnly"/>

$<$ ElementType name="REPRESENTATIVE"

content $=$ "textOnly"/>

$<$ ElementType name="ADDRESS" content="textOnly"/>

$<$ ElementType name="PHONE" content="textOnly"/>

$<$ ElementType name="E-MAIL" content="textOnly"/>

$<$ ElementType name="FAX" content="textOnly"/>

$<$ ElementType name="PROJECT" content="eltOnly" order="seq" $>$

$<$ element type="BID_ITEM_CODE" minOccurs="1"

maxOccurs $=" 1 " />$

$<$ element type="AVAIL_PERIOD" minOccurs="1"

maxOccurs $=" 1 " />$
$<$ /ElementType $>$

$<$ ElementType name="AVAIL PERIOD"

content $=$ "textOnly" dt:type $=$ "string"/>

$<$ ElementType name="BID_ITEM_CODE"

content="eltOnly" order="seq">

$<$ element type="BID PRICE" minOccurs="1"

maxOccurs $=" * " />$

$</$ ElementType $>$

$<$ ElementType name="BID_PRICE" content="eltOnly" >

$<$ AttributeType name="WORKING DAY"

dt:type="number"/>

$<$ attribute type="WORKING DAY"/>

$<$ element type="ACTIVITY" minOccurs="1"

maxOccurs $=" * " />$

$</$ ElementType $>$

$<$ ElementType name="ACTIVITY" content="eltOnly"

order $=$ "seq" $>$

$<$ element type="UNIT" minOccurs="1" maxOccurs="1"/>

$<$ element type="AMOUNT" minOccurs="1"

maxOccurs $=" 1 " />$

$<$ element type="UNIT_PRICE" minOccurs="1"

$\operatorname{maxOccurs}=" 1 " />$

$<$ element type="SUM_PRICE" minOccurs="1"

maxOccurs="1"/>

$<$ element type="WORKING_PERIOD" minOccurs="1"

maxOccurs $=" 1 " />$

$</$ ElementType $>$ 


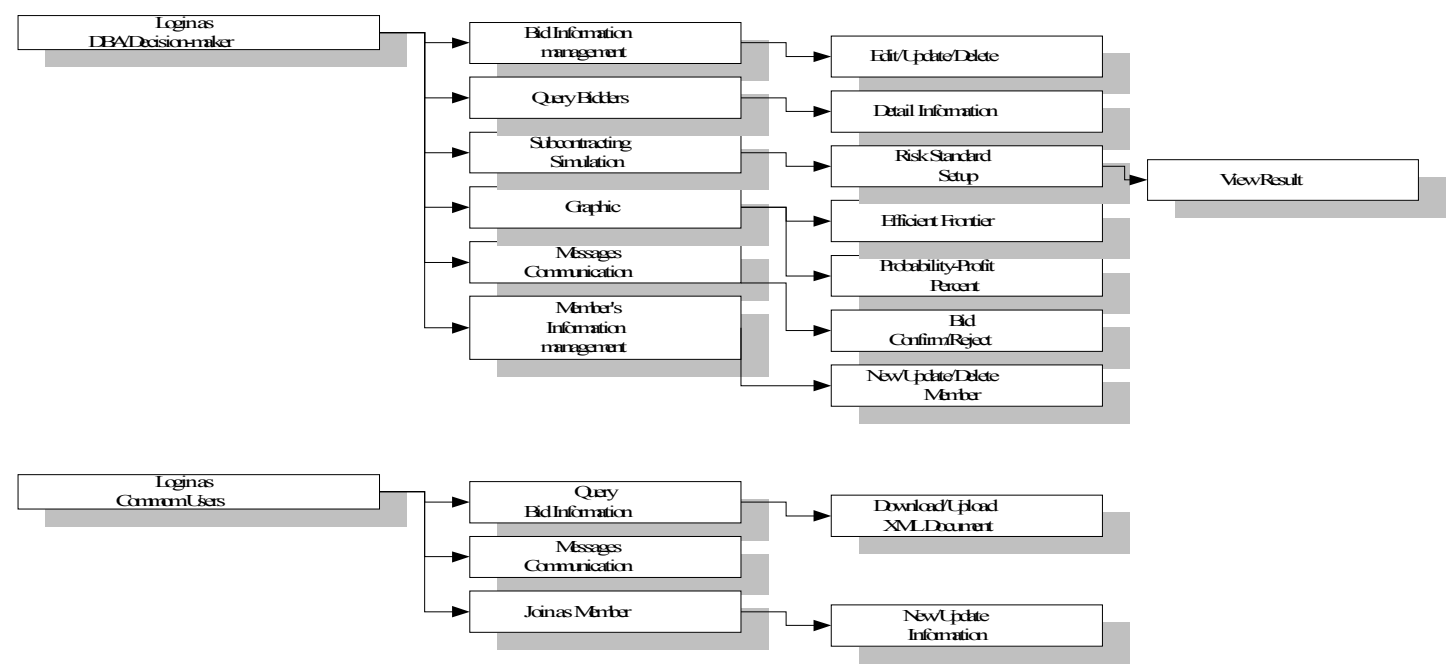

Figure5. The Page Structure of ASAP System

$<$ ElementType name="UNIT" co $\mathrm{dt}:$ type $=$ "string" $/>$

$<$ ElementType name="AMOUNT" content="textOnly" dt:type $=$ "number"/>

$<$ ElementType name="UNIT_PRICE" content="textOnly" dt:type="number"/>

$<$ ElementType name="SUM_PRICE" content="textOnly" dt:type="number"/>

$<$ ElementType name="WORKING PERIOD"

content $=$ "textOnly" dt:type="string" $/>$

$</$ Schema $>$

The above object oriented tree structure of subcontract XML Schema is expressed as figure4. ASAP system is now under construction, but the prototype interface and the details of developing system structure is expressed as figure5 and figure6.

AND FUTURE WORK

This study is a preliminary for applying information technology to subcontract construction project in systematized point of view. The overall subcontracting supply chain is regarded as an integration, and the performance of whole body is evaluated simultaneously. A prototype of web-based decision support system ASAP is now developing for general contractors to easily make an appropriate trade-off between risk and revenue through omnipresent internet. Furthermore, the extensible markup language provides ASAP a remarkable communication standard in messages exchange. Under the processing framework of ASAP, general contractors can greatly improve their subcontracting efficiency and enhance competitiveness in construction industry.

\section{REFERENCE}

1. Williamson, O.E., 1985, "The Economic Institutions of Capitalism: Firms, Markets, Relational Contracting", The Free Press, N.Y. U.S.A.

2. Weston David C. and G. Eward Gibson Jr., 1993, "Partnering- Project Performance in U.S. Army Corps of Engineers", J. of Mgmt in Engrg., ASCE, Vol9, No.4.

3. Gray, C. and Flanagan, R., 1989, "The Changing Role of Specialist and Trade Contractors", Chartered Institute of Building, Ascot, U.K..

4. Hinze, J. and Tracey, A., 1994, "The Contractor-Subcontractor Relationship: The Subcontractor's View", J. Constr. Engrg. And Mgmt., ASCE, 120(2), 274-287.

5. Hsieh,T.Y.,1998, "Impact of Subcontracting on Site Productivity: Lessons Learned in Taiwan", J. Constr. Engrg. And Mgmt., ASCE, 124(2), 91-100. 
6. Eccles,R. G.,1982, "The Quasifirm in The Construction Industry", J.of Economic Behavior and Organization, 2(4), pp335-357.

7. Minder Chen,1999,"XML:Technology and Its Applications in EC", seminar handout, Taipei, Taiwan.

8. Introducing XML/EDI, "The e-Business framework",http://www.geocities.com

9. Russell,J.S. ,Jasellskis, E.J.,Lawrence,S.L.,
Tserng, H. P., and Prestine, M.T.(1996).

"Development of a predictive tool for continuous assessment of project performance." Res.Rep 10712, The CII.,Univ. of Texas at Austin, Austin,Tex.

10. Russell,J.S. ,Jasellskis, E.J.,Lawrence,S.L. (1997). "Continuous Assessment of Project Performance." J. Constr. Engrg. And Mgmt., ASCE, 123(1), 64-71.

11. http://www.rdec.gov.tw/ipcs/guide.htm

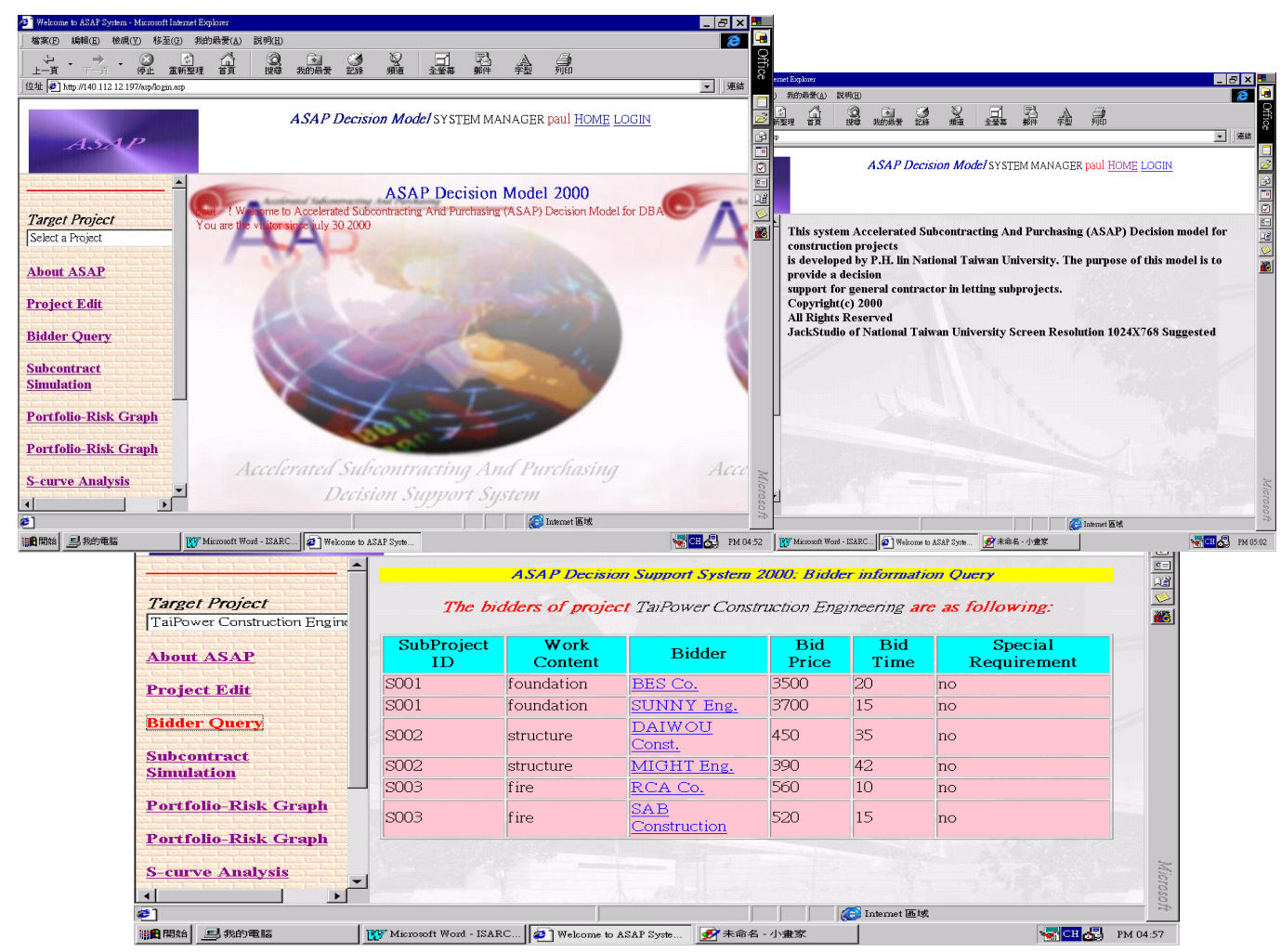

Figure6. Prototype Demonstration of ASAP System 